receptor function and importance in states of chronic hypoxia.

\section{Microanatomy of Glomic Tissue of the Pulmonary Trunk}

c. W. EDWARDS The microanatomical structure and cytology of glomic tissue of the pulmonary trunk in man and animals.

\section{Peripheral Glomic Tissue within the Lung}

H. SPENCER The microanatomical structure of glomic tissue around small pulmonary veins. Possible functional significance. Intrapulmonary chemodectomas.

\section{The Concept of a 'Glomus Pulmonale'}

V. E. KRAHL The concept of a glomus of the sixth branchial arch. Its possible functional significance.

\section{Vascularization of the So-called 'Glomus Pulmonale'}

A. E. BECKER A demonstration that the glomus pulmonale is supplied by the intertruncal branch of the left coronary artery and not by a branch of the pulmonary trunk. The hypothesis that glomic tissue of the pulmonary trunk does not represent a true glomus pulmonale and does not have a true pulmonary chemoreceptor function.

\section{Physiological Evidence for and against the Presence of a Pulmonary Chemoreceptor}

HELEN DUKE

The symposium is supported by demonstrations.

\section{REGULATION OF CEREBRAL BLOOD FLOW IN CHRONIC RESPIRATORY INSUFFICIENCY}

BARBRO EKSTRÖM-JODAL and EGIL HÄGGENDAL Acute changes in the arterial carbon dioxide tension and oxygen saturation have marked effects on the resistance of the cerebral blood vessels so that hypocapnia causes vasoconstriction while hypercapnia and hypoxia cause vasodilatation. In conditions with long-standing alterations in the arterial blood gas situation, however, there has been evidence of normalization of the cerebral blood flow and simultaneously a return of the cerebrospinal fluid $p \mathrm{H}$ towards normal values. This investigation has been performed in patients with chronic respiratory insufficiency. The cerebral blood flow, arterial and cerebral venous blood gases and cerebrospinal fluid composition have been studied during several consecutive days in patients with an exacerbation of the disease and in patients who have been in a 'steady state' in relation to blood gases for a long time. In both groups the blood gas situation has been acutely changed by hyperventilation or inhalation of different gas mixtures.

The cerebral blood flow has been measured with a modified Kety-technique, i.e., a saturation technique using ${ }^{133} \mathrm{Xe}$ as the indicator. Acute changes in cerebral blood flow have been estimated from the arteriovenous oxygen difference.

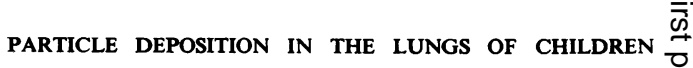
D. C. F. MUIR, A. HISLCP and LYNNE REID There no method at present whereby the site of partic/ deposition in the lungs of human subjects can be determined directly. Our best estimates are base $\$$ on considerations of the size of the particles ant on the dimensions of the airways. Three authors (Findeisen, 1935; Landahl, 1950; and Beeckmans, 1965) have attempted an analysis of this type. Airborne infections and allergic reactions are common in childree and inhalation therapy is widely used in the treatment of children with respiratory disorders. It is thus importan to obtain some idea of the manner in which inhaled particles are handled by the lungs of children. In this paper an attempt is made to understand the particle deposition pattern as a function of age using the mathe matical approach developed by Landahl (1950) fo determining the probability of deposition in different regions of the lung.

\section{PROLONGED SURVIVAL AFTER HUMAN LUNG TRANSPLANTATION}

P. Vermeire AND COLleagues (Belgium) Homotranso plantation of one lung was carried out in a 23-year-ol man suffering from acute silicosis in November 1968 . This patient has survived until the time of writing. H progress and present state will be described on behalf of the team responsible for the operation, which was carried out at the Akademisch Ziekenhuis, Gent. The member $\overrightarrow{8}$ of the team are F. Barbier, P. Vermeire, F. De Rom J. Versieck, S. Ringoir, J. Tasson, H. Lamont, and R. Verbeke.

\section{SOME RADIOLOGICAL STUDIES OF THE PULMONARY CIRCULATION}

Pulmonary Air Embolism: Physiological Aspects

ERIK BERGLUND and STAFFAN JOSEPHSON Pulmonary a embolism was followed by acute pulmonary arteriä hypertension starting within 5 seconds and reversing totally within 15 minutes. Pulmonary blood flow feH by $0-52 \%$ and reversed to control level within one minute.

The role of vasoconstriction in the increased vasculaf resistance was evaluated. Air was injected into only ore lung with the dog in the lateral position. In five dogs 17 air injections $(0.5-2 \mathrm{ml}$. $/ \mathrm{kg}$. body weight) wert performed. The PA pressure rose from an average of $18 \mathrm{~mm}$. Hg to $35 \mathrm{~mm}$. Hg, which is much more than of unilateral PA block. Thus a substantial part of the pressure rise is caused by vasoconstriction. This intet pretation was confirmed by injecting air into a previousfy occluded pulmonary artery: a similar pressor response occurred in 20 of 36 experiments. We believe that thi is due to a nervous reflex, but neither vagotomy now alpha or beta receptor blocking prevents the pressure ris

During embolization the arterial oxygen saturatio falls. Like the pressor response, the saturation change 15 reversible. On unilateral air injection into a previous 